INTERNATIONAL JOURNAL OF SYSTEMATIC BACTERIOLOGY

Vol. 20, No. 4 October 1970

pp. $541-550$

Copyright 1970, Iowa State University Press

\title{
ARE SOME CHARACTERS MORE EQUAL THAN OTHERS?
}

\section{S. T. Cowan}

ABSTRACT. In deciding on the importance of microbial characters much depends on the meaning attached to the word important, and this was discussed in relation to the subordination of characters, an old taxonomic principle in which different kinds of character were associated with different category levels.

In a symposium such as this it is all too easy to accept one feature (in this case cell wall) as the most important character of an organism; this is not mental laziness but the effect of brain-washing. For two days we have listened to experts expounding on the wonders of cell walls which are credited with yielding useful taxonomic information in terms of anatomy, chemistry and serology; the claims made rival those made for DNA by molecular biologists. I use the term brain-washed advisedly, for we have been exposed to concentrated cell walls-and nothing but cell walls - and a stranger in our midst could be excused for believing that bacteria are made up entirely of cell walls and their appendages. It is my mission to try to redress the balance (for it is not true that bacteria are entirely made up of cell walls) and, as a general taxonomist, try to evaluate what we have heard and, more particularly, put it in proper perspective relative to the many other features that go to make up the bacterium.

The problem divides itself into three parts: (i) to list the kinds of character that are used in taxonomic work, (ii) to try to pick out those that are most informative ahout the inherent nature of the organism and its relationship to others, and (iii) discuss what we mean by the word important when we use it in taxonomy. Some of this I have done before (Cowan 1968).

\section{Kinds of Characters}

Morphology has not been discussed in detail in this symposium, although the cell wall undoubtedly makes the major contribution to the shape of any microorganism. Most of us limit our morphological studies to the crude shape (I recognize only three, spheres, rods and spirals), arrangement (clumps, packets, and chains), presence or absence of motility (from which we predict whether the organism is or is not flagellated), spores and capsules. Dr. Hageage has warned us that electron microscopy may add to our confusion, but fimbriae (also called pili) are difficult to detect except by its use. We may however, use indirect methods such as the adsorption of red cells to assume their presence. These fimbriae also have something to do with sex, but this is a subject which is outside the laboratory experience of the microbial taxonomist. Bound up with morphology are the staining reactions of the microbial cell, and 
these depend both on the permeability of the cell membranes to the stain and stain complexes, and to the reactivity of the cell structures with the particular stain.

There is a well-known taxonomic principle, the subordination of characters, which we can apply to our problem. This means that certain kinds of character are used for the definition of taxa of one category and other kinds are used for higher or lower categories. We cannot deny the importance of morphological characters; in fact, the highest categories (or ranks) of bacteria are usually based on morphological features. We distinguish between branched and unbranched rods, between those that have rigid and those that have flexible cells, between those in which the cell is spiral shaped and those in which it is not; these are the kinds of character that we use to define bacteria in the categories we call Order and Family (Table 1).

Differences in stainability are more restricted and, in bacteria, are limited to the reactions to two staining methods, Gram and Ziehl-Neelsen; both methods are useful but, as they are affected by extraneous factors such as $\mathrm{pH}$, age of the culture, and the nature of the medium in which the culture is grown, they must be interpreted with caution. While the shape of the bacterium depends on the intact cell wall, its staining characteristics depend on its permeability and chemical nature. Dr. Doetsch has reminded us that the site of insertion of flagella is not random but depends on the structure of the cell wall. We should, perhaps, reconsider our modern neglect of the type of flagellation.

We do not limit our characterization to shape and surface structure; we observe characters such as inclusions of fat and other ('metachromatic') bodies, and the nuclear material of the bacterium, though this last is often considered to be a feature of more interest to the biochemist than to the cytologist or to the taxonomist.

The chemical nature of the different parts of the bacterial cell, insofar as we know it, starts with the cell wall and cell membrane. In the basal mucopeptide component of the wall are amino sugars and amino acids and the presence or absence of these wall polymers may be related to the taxonomy of the bacteria. In some bacteria the cell walls contain teichoic acids, and different teichoic acids may be associated with different species. However, both Drs. Work and Gooder have expressed doubts about the usefulness of the wall polymers in taxonomy. The correlation of the chemistry and the taxonomy depends on accurate identification and good classification, as was shown many years ago when Cummins and Harris (1956) found some unexpected discrepancies; in their examination of cell wall extracts of Corynebacterium pyogenes the chromatogram was different from that of all the other corynebacteria and, indeed, closely resembled that of streptococci. A check by classical taxonomic methods indicated that $C$. pyogenes was a misfit in that genus and that characteristics of a streptococcus had been overlooked. Thus the taxonomic indication given by the cell wall hydrolysate was more accurate than the 'placing' by intuitive methods, and provided evidence that cell wall chemistry was a significant tool which, for Gram-positive bacteria at least, demarcated taxa that were 'good' genera.

The cell wall chemistry of Gram-negative bacteria has been studied in other ways; there has been much more intensive work on the serology of the $O$ antigens of Gram-negative than of Gram-positive bacteria, and Dr. Nikaido has summarized for us the results of Westphal and his 
Table 1. Morphological and cytological characters available to the taxonomist.

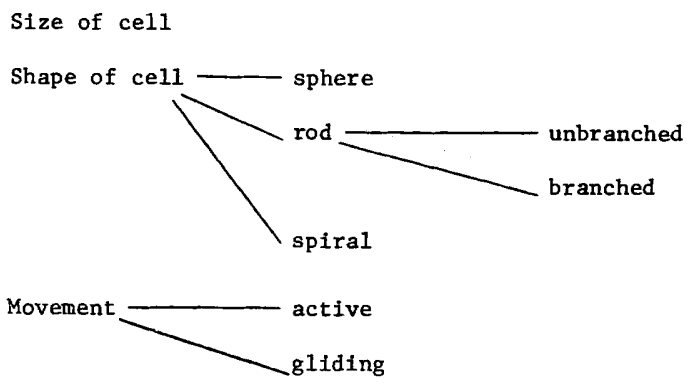

Capsule

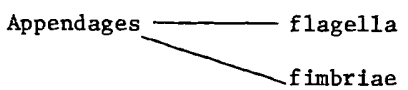

Inclusions

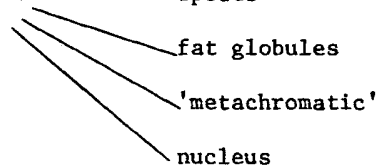

Cell wa11

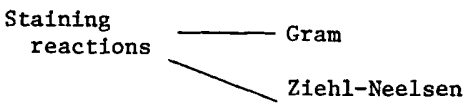

colleagues on the sugar components of 'chemotypes,' which, even if they do not show exact correlations, show a remarkable similarity in the kinds of enteric bacteria they group together. For example, Salmonella adelaide, Arizona serotype 20, and Escherichia coli serotype 1 Il:B4 all cross-react serologically by virtue of similar $O$ antigens, and they also have the same sugar pattern of their $\mathrm{O}$ antigens (Table 2).

Polysaccharide antigens are found in capsules, and in pneumococci are responsible for the type specificity of the organism.

Flagella are protein in nature, and the protein flagellin has a characteristic composition of 14 amino acids. Stocker (1956) has suggested that the multiplicity of $\mathrm{H}$ antigens found in the enteric bacteria is determined by different arrangements of the amino acids. Dr. Pine seems to think that bacterial phylogeny is revealed by biochemistry, but if that is the accepted view of the biochemist, it is not one shared by the microbial taxonomist.

To summarize this section: the chemical nature of the cell surface is taxonomically significant and operates at three levels: 
(i) genus: amino acids and amino sugars of the wall.

(ii) species: teichoic acids of the wall,

(iii) subspecies or serotype: polysaccharides of capsules, amino acids of flagella.

Table 2. Chemical and serological make-up of cell characters

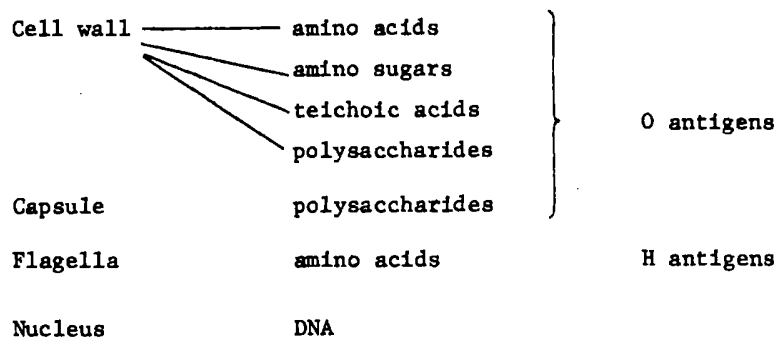

We cannot leave the chemistry of the cell without brief mention of the cytoplasm and cell contents, which, of course, include the nuclear material. The relations between DNA homology and cell wall structure have been discussed by Dr. Johnson, who stressed the importance of nucleotide sequence. This naturally leads on to a consideration of hybridization among bacteria, which is probably only successful when both partners belong to the same genus; so-called intergeneric hybridizations are suspect and suggest the need for us to re-examine our generic circumscriptions. DNA homology, or lack of it, can justify or discredit a genus, and this is well seen in Neisseria, some species of which seem to be badly located when placed in this genus (Bovre 1967, Kings bury 1967).

Tab1e 3. Nineteenth century characters used by taxonomists

Colony form

Change in medium

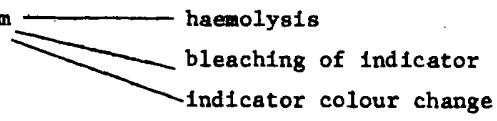

Growth In broth

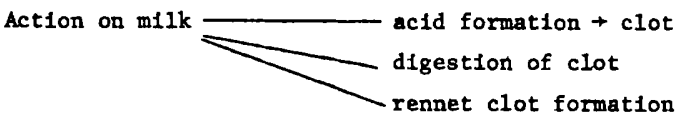

Gelatin stab

Pigment production 
What I call Nineteenth Century Characters consist of those features that can be described and recorded; collectively they are also known as cultural characters but this term is as vague as 'taxonomic character' since all characters are both cultural (in the sense that they are observations on cultures) and taxonomic (since each character contributes to the description of the organism). To call them Nineteenth Century Characters is explanatory of their place in taxonomy, for in the last century they were the characters on which taxonomists depended and the only ones, apart from morphology, that could be used to describe bacteria. They include such features as colony form (size, elevation, surface, edge, consistency, pigmentation), haemolysis on blood agar, appearance of growth in broth, type of growth in gelatin stab cultures, change of indicator in milk and in sugar solutions, clotting and digestion of clot in milk, and liquefaction of inspissated serum. Many of these characters are subjective (e.g. in the description of a colour) and all are influenced by temperature and duration of incubation, and the nutritional qualities of the basal medium; in other words, they are variable because many of the factors that affect them are difficult to control. (Table 3).

Table 4. Physiological characters

Growth requirements

$$
\begin{aligned}
& \text { Atmosphere } \\
& \mathrm{C} \text { and } \mathrm{N} \text { sources } \\
& \text { Essential growth } \\
& \text { factors }
\end{aligned}
$$

Trace elements

Temperature

\author{
air, oxygen, $\mathrm{CO}_{2}$ \\ organic, inorganic \\ haemin, co-enzyme I
}

range, optimum

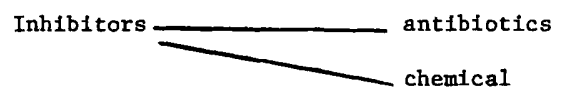

An extension of the last group of characters is seen in what are described as the growth requirements and the physiology of bacteria. It is still useful to know what media encourage and what discourage growth; what substances are essential and which inhibit growth. A refinement of this listing of media and stimulating/inhibiting substances is to study the actual growth requirements of bacteria; instead of using infusions of meat we prepare defined media (often incorrectly called synthetic) so that we can express the minimal nutritional needs in terms of amino acids, sugars, salts, and so on. We are much more scientific than our forebears, but we should not be too self-satisfied for not all bacteria are accommodating and several pathogens demand animal tissue in which to multiply. But if we avoid the difficult organisms (and biochemists always do) we can describe our bacteria very prettily by naming the carbon and nitrogen sources that can be utilized, and list the trace elements and essential growth factor 8 that are required. Antagonists are taxonomically as interesting as growth stimulants, and the description of a 
bacterium is seldom complete without reference to a list of antibiotics to which it is susceptible, and another list of those to which it is resistant. Some bacteria produce bactericidal substances, bacteriocins, but production of the se may be a strain characteristic so that this ability may not be taxonomically significant.

Under the general heading of physiology we are concerned with growth as it is affected by extraneous influences acting simultaneously; these may be (i) physical factors such as temperature and humidity, (ii) chemical factors such as the atmosphere in which growth occurs, whether oxygen can or cannot be used, and so on. The third group (iii) of factors are physico-chemical, such as $\mathrm{pH}$ value of the medium, and the molarity of salts in the medium (Table 4).

It would be foolish of me to say that these nutritional factors are more or less important than any other kind of feature, but it is quite obvious to the unbiased that, say, compared with morphological characters, the two kinds of feature are not only different in themselves but that they are expressing different differences (or divisions).

What are often called the biochemical characters are those we determine by simple biochemical tests which give us some idea of the enzymatic make-up of an organism. Within recent years attention has been focussed on respiration, or the katabolism of carbohydrate which may be broken down and utilized by anaerobic fermentation or by oxidation (which provides twenty times as much energy as fermentation), or by a combination of both methods. Fortunately, there are simple tests by which the kind of respiration can be discovered, and many bacteriologists have chosen this character as a linch-pin about which all taxonomic problems revolve, thus giving it an importance that may be challenged (Table 5).

Table 5. Metabolic characters

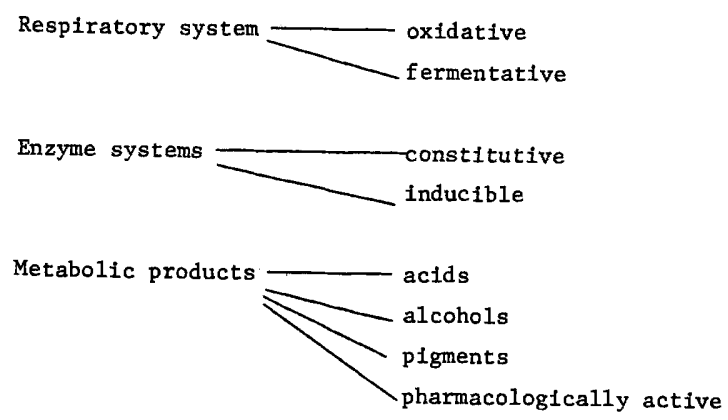

A bacterium that is a pathogen is much less likely to be misidentified than a nonpathogen; the fact that it was isolated from a sick animal or a wilting plant is a pointer to its correct identification. But the pathogenicity of a bacterium for an animal, plant, or even another bacterium, should not render it any more meritorious in the eyes of the taxonomic beholder. Unfortunately, the economic and epidemiological significance of a pathogen has made its recognition a matter of concern to veterinary, medical, horticultural, and agricultural interests and increased its 
Table 6. Other kinds of character available to taxonomists
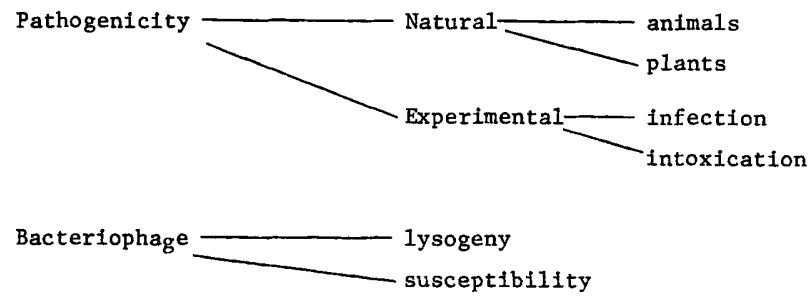

importance to the word at large, with the result that outside pressure has enhanced the value of this one character out of all proportion to its worth in taxonomy. In the host pathogenicity is often an assumption, and although a logical one, it can only be proved by infection of another member of the host species (Table 6).

Finally, we come to the taxonomic relations between the bacteriophage and the host bacterium, which may be of one of two kinds; either the bacterium carries a phage to which it is not susceptible (this is lysogeny), or the bacterium may be susceptible to one or more phages, and the pattern of susceptibility may be characteristic. In either event, the taxonomic level of the bacterium that is determined by the phage is a low one.

\section{Importance?}

In this brief discussion of the kinds of character we use in bacterial taxonomy I have several times used the words important, valuable, or significant, and it is now time to consider what we mean by these terms. I have used the terms synonymously, as a form of what Fowler calls 'elegant variation,' so here we need discuss only one of them, and I will take the simplest of the words, the one most easily understood, important. Important surely needs some qualification; important for what? Here we are thinking in relatively narrow terms; we are dealing with important (or importance) as it concerns the taxonomist, and, narrowing it still further, as it concerns him in his evaluation of microbial characters. To estimate what he means in this context by the word important, we want to know what he does with the characters, and, in particular, if he grades them and arranges them in some order. There are two questions here which should be separated.

(1) What does the taxonomist do with characters? He uses them to describe bacteria, for it is from the description that he obtains a mental picture of the organism, and by the description passes on that picture to others. Whether the organism is previously known or unknown, the taxonomist uses the description (or characters) so that he (and others) will know when he has two or more of a similar kind, and he recognizes the similarity by the number of characters shared by the individuals, the greater the number of shared characters the greater is the similarity and when (if ever) all the characters are alike the organisms being compared are known to be identical. The taxonomist uses characters to find likenesses or similarities. 
(2) Does the taxonomist grade characters, or arrange them in some order of merit? It is an unconscious habit to make comparisons, and the taxonomist is no exception when he compares different characters and weighs their usefulness to him. Let us suppose that a taxonomist has cultures of the species we know as Escherichia coli and Chromobacterium violaceum; quickly he can distinguish them by the pigment produced by one of them, but when he stains films by Gram's method he cannot distinguish them for they are both Gram-negative rods without any distinctive features. Clearly, he thinks, pigment production is more valuable than the Gram reaction, and he rates (or grades) it more highly. But if his two cultures had been $C$. violaceum and $C$. lividum and he had observed only the same two characters, he would not have rated pigmentation any higher (because both species produce a violet pigment) than the Gram reaction. These examples show that two characters will be evaluated differently at different times, or when there is a different reason for making the comparison. The important word in that sentence is different, and it deserves its repitition; it is perhaps, a clumsy way of rephrasing the old saw 'every case must be dealt with on its own merits.' In this instance the taxonomist, in making his comparisons, is looking for differences that will enable him to distinguish between different bacteria; he is looking for differentiae, and when he finds characters that are of different values to him he grades them.

The answers to our two questions can now be considered together; to question (1), what does he do with characters?, we found that he was using them to group similar organisms together, in other words, he was pigeon-holing, sorting, or classifying. The answer to question (2), does he grade characters?, is that he consciously or unconsciously arranges his characters according to their value in what he is doing - this time separating different organisms, or identifying them with known ones. An important difference in these activities is that in sorting or classifying he is comparing several characters at one time, whereas in picking out, or identifying, he is more likely to be using one or two characters at a time, and he learns from experience that, for the purpose he has on hand and with the kinds of bacteria he is dealing with, some characters will be more informative (and therefore useful or important) than others. As with characters, so with tests for showing characters; some tests will be more valuable (because they are more selective) than others in making an identification.

To a taxonomist thinking of characters, the word important really means useful or helpful; in relation to characters he will regard them as being of more-or-less equal importance for sorting (or classifying), but for identification or for picking out one of a known kind he will find that characters vary in their usefulness, and he will grade them according to their value to him for that particular purpose. But we should recognize that even in classification there is an apparent grading; this is because there is not one universal classification of bacteria, but many different classifications, some general, some specialized, but each having a different purpose and therefore a different emphasis. These classifications will differ from each other in the divisions and subdivisions that are made, and these differences will be reflected in the criteria (characters) chosen to bring them out most clearly. This selection of characters for a special purpose may appear to be stressing those characters, but in fact it is not a weighting, but a re-arrangement of characters, so that different ones become the distinguishing characters. 
So, as a general taxonomic principle, we can say that characters are of equal importance in classification, but of unequal importance in identification; to answer the question posed by the title of this paper (are some characters more equal than others?), we need to look at the circumstances (identification) in which characters do have different values which (when and where?) are most important to $\bar{u}$.

\section{The Top Ten}

Historians of the future will be able to judge the present era from the results of ballots, polls, and lists of 'top tens,' for the $1960 \mathrm{~s}$ have been characterized by gradings of people and things, from the sale of pop records to the popularity of politicians. Consequently, it will be in the modern idiom to grade characters in the order of their importance to us, but we should specify our reason(s) for doing so, for these lists will vary with the purpose specified as much as lists of popular film stars or footballers based on polls made in Europe and in the United States. The analogy with popularity polls is an apt one, for football fans on the two continents will be choosing from different teams of players, and bacteriologists working in one discipline will use characters (or tests) not used by colleagues in other disciplines. Even if we limit ourselves to identification, there will be need for different lists for diagnosticians doing different kinds of work. Most identification work is done by applied bacteriologists not greatly concerned with taxonomy, and it will be obvious that, to a sanitary bacteriologist, the pathogenicity of a bacterium for a plant is not worthy of even a fleeting thought, which means that, for him, its value or importance is zero.

As this symposium has been concerned with cell walls, it is fitting that I should end by expressing my opinion of their place in a list of top ten characters most useful for general identification work. Let me say at once that cell walls will obviously be among that top ten, along with shape, stainability, GC content of DNA, respiration, nutritional requirements, enzymes such as catalase and oxidase, pathogenicity, and .... but I am getting near the tenth and should pause. For different purposes, the order of merit will be different and for a general identification scheme I hesitate to name the sequence. Rather would I commend to your notice diagnostic tables such as those prepared by the late Dr. Steel and me some years ago (Cowan and Steel 1961, 1965), and beg you to assume that, of the top ten, none is more equal than another.

\section{Literature Cited}

Bövre, K. 1967. Transformation and DNA base composition in taxonomy, with special reference to recent studies in Moraxella and Neisseria. Acta path. microbiol. scand. 69:123-144.

Cowan, S. T. 1968. An assessment of the value of biochemical and serological techniques in microbial taxonomy. In Chemotaxonomy and Serotaxonomy, ed. J.G. Hawkes, 269-278. London: Academic Press. and K. J. Steel. 1961. Diagnostic tables for the common medical

bacteria. J. Hyg., Camb. 59:357-372. and 1965. Manual for the identification of medical bacteria.

Cambridge: University Press. 
Cummins, C.S. and H. Harris. 1956. The chemical composition of the cell wall in some Gram-positive bacteria and its possible value as a taxonomic character. J. gen. Microbiol. 14:583-600.

Kingsbury, D. T. 1967. Deoxyribonucleic acid homologies among species of the genus Neisseria. J. Bact. 94:870-874.

Stocker, B.A.D. 1956. Bacterial flagella: morphology, constitution and inheritance. Symp. Soc. gen. Microbiol. 6:19-40. 